\title{
Caregivers' Perception and Practices on Malaria in Children Under Five in EkombeBonji Health Area, Kumba Health District, South West Region of Cameroon
}

\section{NkengafacNyiawung Fobellah ${ }^{1 *}$, Anna Njunda Longoh ${ }^{2}$, FolefockAjua Richard Medterrand ${ }^{3}$ and Efengo Vanessa ${ }^{4}$}

${ }^{1}$ Lecturer, School of Health and Human Sciences, St Monica University, Buea, Cameroon

${ }^{2}$ Lecturer Faculty of Health Sciences, University of Buea, Cameroon

${ }^{3}$ Regional Coordinator of Malaria, West Region, Cameroon

${ }^{4}$ Masters student at International relations Institute of Cameroon, University of Yaounde I, Cameroon

${ }^{*}$ Corresponding Author: NkengafacNyiawungFobellah, Lecturer, School of Health and Human Sciences, St Monica University, Buea, Cameroon.

DOI: 10.31080/ASMS.2020.04.0693
Received: May 25, 2020

Published: July 21, 2020

(C) All rights are reserved by

NkengafacNyiawung Fobellah., et al.

\begin{abstract}
Background: Malaria is one of the diseases which contribute significantly to morbidity and mortality in Africa with $91 \%$ of deaths being children under-five. Despite all efforts to combat malaria, this disease still remains the leading killer of under five children killing a child every minute. Malaria usually progress to its severe state within a very short period of time. Generally mothers/caregivers are the first to recognize fever in children and also determine the decision to seek care. Therefore, recognition of the symptoms of malaria by caregivers and their practices toward seeking treatment is invaluable in order for malaria to be treated in a timely manner. Objectives: The objective of this study was to determine the prevalence of malaria in children under five, and also to investigate the local perceptions, practices and treatment-seeking behaviour for malaria among their caregivers.

Methodology: This study was a cross sectional descriptive, community based study done from January to march 2014 . Children under five years were enrolled for the study. Malaria RDT was done for parasitological evaluation. Questionnaires were administered to children's caregivers to collect socio-demographic data, knowledge regarding malaria, preventive measures and treatment seeking behaviours.

Results: Of the 350 children examined, 174 (49.7\%) [95\% CI: 44.37- 55.07\%] were infected with malaria (plasmodium falciparum). Male and females were similarly infected ( $41.4 \%$ vs. $51.6 \%$ ) with no significant difference $(\mathrm{p}=0.4)$.The prevalence appeared to be highest 41 (23.6\%) in the age group [24-36] months. Caregivers 280(80\%) had proper knowledge on malaria with 316(90.3\%) mentioning mosquito bite as the cause of malaria. Likewise fever/hot body was perceived as the commonest symptom of malaria by 332 (95\%) of caregivers [95\% CI: 91.9-987\%]. With regards to caregivers' practices on prevention, 308(88\%) use insecticide treated nets (ITN) as a preventive method. Only 205 (58.6\%) of caregivers sought treatment at the health facility when their child was ill. As few as 119 (34\%) did so within 24 hours of onset of symptoms. The most common home remedies employed were tepid sponging and use of anti pyretics.

Conclusion: Caregivers had a good knowledge of malaria (including its aetiologic agent, signs and symptoms and preventive measures). They also had a good practice towards preventive measures. However, the prevalence of malaria in under-five was high and only a lesser majority of caregivers sought treatment at the health facility in a timely manner.
\end{abstract}

Keywords: Caregivers; Under-Five Children;EkombeBonji; Cameroon 


\section{Introduction}

Malaria infection has been one of the greatest health problems in the developing world for years and it is still a major health issue till date with an estimated yearly death rate of about 660,000 people. Most of these victims are children less than five years of age[1-3]. The disease still occupies the number one position among diseases of global public health importance[4-6]. It represents $20 \%-50 \%$ of all consultations in health centre and is the greatest cause of mortality in hospitals[7]. Even though it is both preventable and curable, it accounts for $10 \%$ ofdisease burden[4].

Malaria progression to its severe state is usually within a very short period of time, especially in children where severity can occur within 24 hours of onset of symptoms. To reduce morbidity and mortality of malaria, WHO has developed strategies which include as one of its main component the early diagnosis and prompt treatment of malaria[8].

Early diagnosis and treatment of clinical malaria and promotion of ITN constitute the current malaria control strategies in Cameroon. To achieve this goal the government since 2003 has put the following measures; free distribution of ITN especially to pregnant women and children under five; subsidizing the cost of ATCs; and training of community health workers[9]. Despite all this efforts, malaria continuous to be a major cause of morbidity and mortality, accounting for 30 to $35 \%$ of the total annual deaths and $35 \%$ of childhood mortality. It is estimated that $41 \%$ ( 8.2 million people) suffer at least one episode of malaria per year with majority of them being pregnant women and children[10].

All over Africa children under five are highly affected by malaria. In Congo the prevalence of malaria in under five children is $39.3 \%[11]$. According to the Cameroon's $4^{\text {th }}$ Demographic Health Survey (DHS) report of 2011, the prevalence of malaria in children less than 5 years of age was $30 \%$ nation-wide[9].

Generally, mothers or caregivers are the first to recognize fever in children and also determine the decision to seek care. Therefore, recognition of the symptoms of malaria by caregivers and their practices toward seeking treatment is invaluable in order for malaria to be treated in a timely manner.

In our milieu, it is not known whether enough is known about the plasmodium parasite by the caregivers. Also, even in knowl- edgeable individuals, little is known about their practices and treatment seeking behaviour on childhood malaria.

\section{Materials and Methods}

The study was a descriptive, cross-sectional community based study was conducted in the EkombeBonji health area in the months of February and March 2014. Children under the age of five were enrolled in this study. Also caregivers of these children were needed to collect socio-demographic data, knowledge regarding malaria, preventive measures and treatment seeking behaviours. The study was conducted in the Ekombe health area, Kumba health District, Meme division, Cameroon.

Kumba is the head quarter of Meme Division in the South West Region of Cameroon. It is located in the Northern part of this Division with a total surface area of $286 \mathrm{~km}^{2}$. Kumba has a population estimated at over seven hundred thousand $(700,000)$ inhabitants.

The Kumba Health District is made up of 12 Health areas, and has a total population of 284,291 inhabitants[12]. The EkombeBonji health area is made up of 9 communities (Small Ekombe,Three corners Ekombe, EkombeBonji, Marumba I, Marumba II, Kingdongi, BaiBicon, Baimanja, Baimetoko) with an estimated population of under-fives at 3072.8 (16.9\%)[12]. The major ethnic groups are the Bafaw, Bakundu, Oroko and the Balue. The main economic activity of the population is agriculture.

\section{Study population}

Children aged 6-59 months with their caregivers, living in the EkombeBonji Health Area, were recruited by means of cluster sampling during household visiting.A household was defined as a person or group of people living in the same house, who are answerable to the same head and share a common source of food and/or income[13]. The health area was divided into 9 communities each representing a cluster. A listing of all the clusters/settlements was made to form a sample frame, one of which was randomly selected.

\section{Inclusion criteria}

- $\quad$ Children under five years living in the Ekombe Health Area.

- Children from all origins, without discrimination of sex, ethnicity and religion.

- $\quad$ Caregivers who agreed to sign informed-consent forms. 


\section{Exclusion criteria}

- $\quad$ Children under five years of age with no caregiver.

- All caregivers who will refuse to sign the consent form.

\section{Sample size calculation}

The sample size of 322 subjects estimated using the formula below[14]:

$\mathrm{N}=\frac{\mathrm{PQ}\left(\mathrm{Z}^{2}\right)}{\mathrm{d}^{2}}$

Where:

$\mathrm{N}=$ Minimal Sample Size

$\mathrm{P}=$ Prevalence of a given condition = Prevalence of Malaria in under five children in

Cameroon[9] $=30 \%$

$\mathrm{Q}=$ InversePrevalence (1-P)

$\mathrm{Z}$ = Standard normal variate for a confidence level of $95 \%=1.96$

$\mathrm{d}=$ Degree of precision $=0.05$

$\mathrm{n}=322$ subjects.

\section{Study procedures}

\section{Preparation for data collection}

- A training session involving the chief investigator and four health personnel of the Ekombe health centre was organized to practice rapid diagnostic testing to ensure quality control, and also for pre-testing of questionnaire.

- In order to facilitate response, sensitization about the research work was carried out in the locality of the Ekombe Health Area after seeking authorization from the community council and the chiefs.

- The cluster sampling method was used in order to choose participants for the study.

- Each caregiver was given an informed consent form for approval in order for them and their children to be involved in the study.

\section{Data collection}

\section{Sampling procedure}

The cluster sampling method was used. EkombeBonji health area is made up of 9 communities. Numbers were allocated to each of the 9 communities and balloting was done where by EkombeBonjiwas selected. All under-five children of that community with their corresponding caregivers were involved in this study during household visit. Prior to data collection, a consent form was presented with explanations of the study. A second balloting was not done as thesample size was met by the first community. The starting point was determined by spinning a bottle within the village square and picking the first house that is closest to the mouth of the bottle. The household without an eligible child was skipped and the next closest household visited.

\section{Pre-coded questionnaires}

A short structured questionnaire was administered to caregivers of these children during which interviews were done and data recorded in these questionnaires. This questionnaire comprises of sections $\mathrm{A}$, and $\mathrm{B}$ :

- The sociodemographic information of both the child and the caregiver. This includes information such the gender and age of child, gender, age, occupation, marital status and educational level of the caregiver;

- Caregivers knowledge on malaria including attitudes and practices;

- Clinical data which includes axillary temperature $\left({ }^{\circ} \mathrm{c}\right)$ and rapid diagnostic test results for each child. A sample of questionnaire is shown in the appendix.

\section{Laboratory investigations}

Following administration of questionnaires, Capillary blood samples of children under-five was collected and a Rapid Diagnostic Test (RDT) performed.

\section{Principle of RDT}

A spot rapid diagnostic test using a labeled CareStart Malaria HRP2 (Pf) test was performed. Malaria RDT detects specific antigens (proteins) produced by malaria parasites. These antigens are present in the blood of infected or recently infected people. The RDT signifies their presence by a colour change on an absorbing nitrocellulose strip.This procedure involved the following materials: An unopened capillary test packet, a new capillary tube, a new unopened alcohol swab, a sterile lancet, and disposable gloves.

A test packet was opened and the cassette removed. Using an alcohol swab the child's $4^{\text {th }}$ finger was cleaned and air-dried. Using a sterile lancet this finger was pricked toward the side of the pulp. With the aid of a capillary tube, the blood-drop formed on the fin- 
ger was collected, and then placed in the cassette well. Four drops of the diluents assay was added, and then timing started. Results were read and recorded in the questionnaire[15].

\section{Interpretation of the test}

- Two bands: The presence of two colour bands, "C" control and "T" test indicates $P$. falciparum positive results(Figure1).

- One band: negative: The presence of one colour band (“ $\mathrm{C}$ ” control line) within the result window indicates a negative result (Figure2).

- Invalid result: This is when we have colour bands in "C" and " $\mathrm{T}$ " or when there is a colour band in "T" and no colour band in "C"(Figure 3).

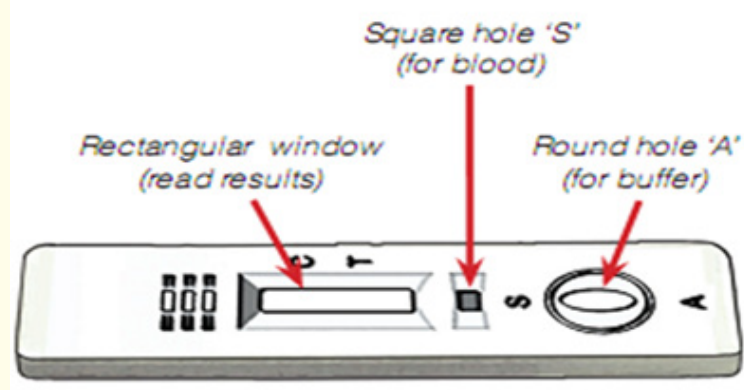

Figure 1: Invalid RDT.
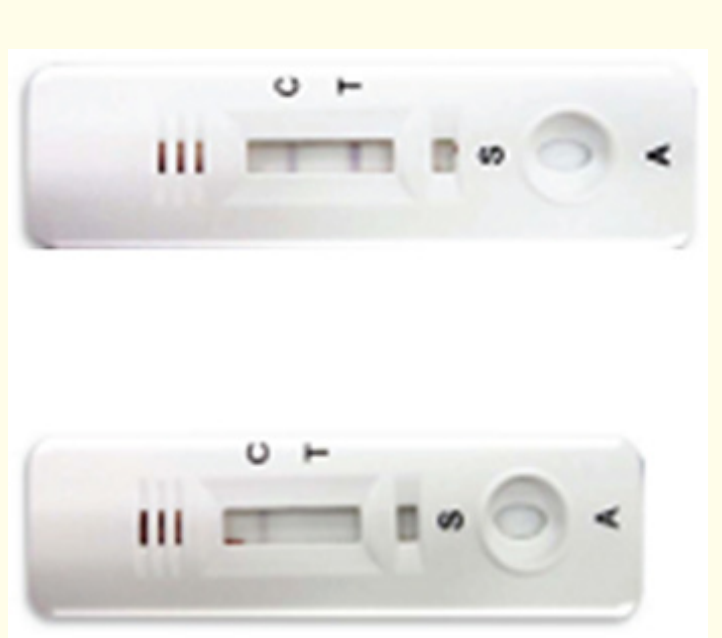

Figure 2: Positive RDT.
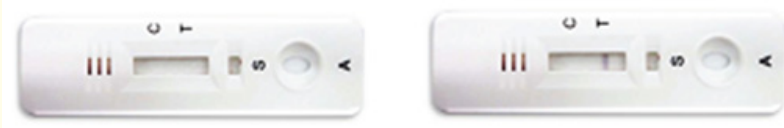

Figure 3: Negative RDT.
If the control band (" $c$ ") failed to appear within the result window, the result considered invalid. The specimen was thus retested. All tests results were recorded in the questionnaire and also communicated to child's caregivers, explaining to them the significance of the results. Symptomatic subjects were prescribed Amodiaquine/Artesunate combination therapy and paracetamol (as need be) as recommended by the national policy for malaria treatment.

\section{Data management and analysis}

Data collected were analyzed using SPSS version 16 computer software to produce frequency tables. Data was entered and cleaned by consistency checks. Collected data was stored as different folders on the same computer and two USB mass storage devices were used as primary and secondary backup sources for the data and a tertiary backup was done in a private mail box on internet.

Descriptive analysis was used to describe the sociodemographic data of the children and their caregivers, and all objectives in the study and displayed as mean frequency and percentages tables. For objectives one and three, a P value $<0.05$ was considered significant.

\section{Study Limitations}

This study was limited by the fact that some caregivers could have given incorrect information because of the fear of being exposed. To solve these problems it was explained to the participants that information given shall be kept confidential, and also questionnaires were coded with numbers.

\section{Ethical considerations}

The study protocol was reviewed and approved by the ethical review committee of the Faculty of Health Sciences of the University of Buea, Faculty of Health Sciences Institutional Review Board (FHIRB) prior to beginning of the field work. Administrative clearance for the study was obtained from South West Provincial Delegations of Public Health. Also, authorization was obtained from the Kumba district medical officer, the community council and the quarter-head.

The principle of justice was respected, that is, the caregivers/ childhad the right to participate in the study or not and was not to experience any prejudice due to the fact that he/she did not agree to participate or for one reason or the other decided to abandon the study.

All parents were informed on the goals and interest of the research; and confidentiality of data collected and anonymity during publication of results was respected through attribution of child identification number. 
All children found to be infected and symptomatic were prescribed Artesunate/Amodiaquine tablets (Artesunate 4mg/kg/day, Amodiaquine $10 \mathrm{mg} / \mathrm{kg} /$ day) or Arthemeter/Lumefantrine tablets.

\section{Sociodemographic data of participants}

\begin{tabular}{|l|c|c|}
\hline \multirow{3}{*}{ Gender of child } & & Number (\%) \\
\cline { 2 - 3 } & Male & $153(43.4 \%)$ \\
\cline { 2 - 3 } & Total & $350(100 \%)$ \\
\hline Age group (months) & $6-12$ & $77(22.0 \%)$ \\
\cline { 2 - 3 } & $13-24$ & $88(25.1 \%)$ \\
\cline { 2 - 3 } & $25-36$ & $79(22.6 \%)$ \\
\cline { 2 - 3 } & $37-48$ & $37(10.6 \%)$ \\
\cline { 2 - 3 } & $49-60$ & $69(19.7 \%)$ \\
\cline { 2 - 3 } & Total & $350(100 \%)$ \\
\hline
\end{tabular}

Table 1: Distributions of age and gender of children

\begin{tabular}{|c|c|c|}
\hline Characteristics & & Number (\%) \\
\hline \multirow{2}{*}{ Gender of caregiver } & Female & $315(90 \%)$ \\
\hline & Male & $35(10 \%)$ \\
\hline \multirow{5}{*}{$\begin{array}{l}\text { Age of caregivers } \\
\text { (years) }\end{array}$} & $21-30$ & $214(61.1)$ \\
\hline & $31-40$ & $108(30.9 \%)$ \\
\hline & $41-50$ & $15(4.3 \%)$ \\
\hline & $51-60$ & $6(1.7 \%)$ \\
\hline & $>60$ & $7(2.0 \%)$ \\
\hline \multirow{4}{*}{$\begin{array}{l}\text { Educational status } \\
\text { of caregivers }\end{array}$} & No school & $22(6.3 \%)$ \\
\hline & Primary & $171(48.9 \%)$ \\
\hline & Secondary & $152(43.4 \%)$ \\
\hline & Tertiary & $5(1.4 \%)$ \\
\hline \multirow{6}{*}{ Occupational status } & Student & 27 (7.7\%) \\
\hline & Housewife & $134(38.3 \%)$ \\
\hline & Trader & $32(9.1 \%)$ \\
\hline & $\begin{array}{c}\text { Public/private } \\
\text { service }\end{array}$ & $17(4.9 \%)$ \\
\hline & Farmer & $89(25.4 \%)$ \\
\hline & $\begin{array}{l}\text { Hairdresser/ } \\
\text { seamstress }\end{array}$ & $51(14.6 \%)$ \\
\hline \multirow{3}{*}{ Marital status } & Single & $72(20.6 \%)$ \\
\hline & Married & $278(79.4 \%)$ \\
\hline & Total & $350(100 \%)$ \\
\hline
\end{tabular}

Table 2: Socio-demographic Characteristics of caregivers.

Prevalence of malaria in children

The overall prevalence of malaria parasite in this study population was 174(49.7\%) by RDT[95\% CI: 44.37- 55.07\%].The high- est prevalence $[\mathrm{n}=41(23.6 \%)]$ was in the range $25-36$ months. The age range 36-42 had the least prevalence [ $n=23(13.2 \%)]$. Also, females $[\mathrm{n}=102(51.6 \%)]$ were more affected than males [n $=72(41.4 \%)]$. But this was found to be statistically insignificant $(\mathrm{P}$ value $=0.4$ )(Seetable 6 )

\begin{tabular}{|l|c|c|}
\hline \multirow{2}{*}{ Characteristics } & \multicolumn{2}{|c|}{ Positive RDT } \\
\hline \multirow{4}{*}{ Gender } & & Number (\%) \\
\hline \multirow{4}{*}{ Age groups (months) } & Male & $72(41.4 \%)$ \\
\cline { 2 - 3 } & Female & $102(58.6(\%)$ \\
\cline { 2 - 3 } & $6-12$ & $36(20.7 \%)$ \\
\cline { 2 - 3 } & $13-24$ & $40(23.0 \%)$ \\
\cline { 2 - 3 } & $25-36$ & $41(23.6 \%)$ \\
\cline { 2 - 3 } & $37-48$ & $231(3.2 \%)$ \\
\cline { 2 - 3 } & $49-60$ & $34(19.5 \%)$ \\
\cline { 2 - 3 } & Total & $174(49.7 \%)$ \\
\hline
\end{tabular}

Table 3: Distribution of RDT by age and gender of children.

\section{Caregivers' knowledge on malaria in children \\ Causes of malaria}

A majority of caregivers, $[\mathrm{n}=316(90.3 \%)]$ attributed mosquitoes as the cause of malaria[95\% CI: 86.57-93.09\%]. Other causes of malaria mentioned were dirty surroundings and exposure to cold, drinking contaminated water and witchcraft. A small percentage $[n=3(0.9 \%)]$ never knewthe cause of malaria. See table 6 below.

\begin{tabular}{|l|c|}
\hline Signs & Number (\%) \\
\hline Fever/Hot body & $332(94.9 \%)$ \\
\hline Weakness & $135(38.6 \%)$ \\
\hline Vomiting & $132(37.7 \%)$ \\
\hline Loss of appetite & $99(28.3 \%)$ \\
\hline Chills/shivering & $94(26.9 \%)$ \\
\hline Convulsions & $64(18.3 \%)$ \\
\hline Dark red nearly black urine & $45(12.9 \%)$ \\
\hline Headache & $44(12.6 \%)$ \\
\hline Body pains & $38(10.9 \%)$ \\
\hline Sweating & $26(7.4 \%)$ \\
\hline Anaemia (pallor of palms, conjunctiva) & $18(5.1 \%)$ \\
\hline Splenomegaly & $8(2.3 \%)$ \\
\hline Cough & $6(1.7 \%)$ \\
\hline Diarrhoea & $5(1.4 \%)$ \\
\hline Weight loss & $3(.9 \%)$ \\
\hline Total & $350(100 \%)$ \\
\hline
\end{tabular}

Table 4: Signs of malaria in children. 
Caregivers' Perception and Practices on Malaria in Children Under Five in EkombeBonji Health Area, Kumba Health District, South West Region of Cameroon

\section{Caregivers' perceived signs of malaria in children}

At least one or more signs/symptoms of malaria were mentioned by caregivers. Fever $[\mathrm{n}=332$ (95\%)]was the main sign/ symptom mentioned by caregivers [95\% CI: 91.9-987\%]. Also, we hadweakness [ $\mathrm{n}=135$ (38.6\%)] and vomiting at 132 (37\%). Other symptoms mention were loss of appetite, shivering, body pains, sweating, black urine, convulsion, splenomegaly commonly called "corner belle"(See table 7).

\section{Caregivers knowledge on malaria prevention}

Use of mosquito nets [n = $325(92.9 \%)]$ was the main method of prevention mentioned by the caregivers.Other methods of prevention mentioned were cleaning the surrounding, wearing long dresses on their children, and spraying insecticides. See table 8 below.

\begin{tabular}{|l|c|}
\hline Signs & Number (\%) \\
\hline Fever/Hot body & $332(94.9 \%)$ \\
\hline Weakness & $135(38.6 \%)$ \\
\hline Vomiting & $132(37.7 \%)$ \\
\hline Loss of appetite & $99(28.3 \%)$ \\
\hline Chills/shivering & $94(26.9 \%)$ \\
\hline Convulsions & $64(18.3 \%)$ \\
\hline Dark red nearly black urine & $45(12.9 \%)$ \\
\hline Headache & $44(12.6 \%)$ \\
\hline Body pains & $38(10.9 \%)$ \\
\hline Sweating & $26(7.4 \%)$ \\
\hline Anaemia (pallor of palms, conjunctiva) & $18(5.1 \%)$ \\
\hline Splenomegaly & $8(2.3 \%)$ \\
\hline Cough & $6(1.7 \%)$ \\
\hline Diarrhoea & $5(1.4 \%)$ \\
\hline Weight loss & $3(.9 \%)$ \\
\hline Total & $350(100 \%)$ \\
\hline
\end{tabular}

Table 4: Signs of malaria in children.

\begin{tabular}{|l|c|}
\hline Preventive measures & Number (\%) \\
\hline Sleeping under mosquito & $325(92.9 \%)$ \\
\hline Cleaning the surrounding & $163(46.6 \%)$ \\
\hline Wearing long dresses & $82(23.4 \%)$ \\
\hline Spraying insecticide & $56(16 \%)$ \\
\hline Others (use of drugs, good feeding) & $32(9.1 \%)$ \\
\hline
\end{tabular}

Table 5: Caregivers' knowledge on malaria prevention.

\section{Knowledge score}

A total of seven questions in the questionnaire were used to formulate a score for assessment of the general knowledge of caregivers in this study. These questions comprise of knowledge on the cause, transmission, severity, prevention and treatment seeking behaviour[16].Each of the correct answers were attributed a score of 1 and 0 (zero) if incorrect. A total knowledge score was then derived per caregiver.

\begin{tabular}{|l|c|}
\hline Questions & Number (\%) \\
\hline 1. What causes malaria in children malaria? & $316(90.3 \%)$ \\
\hline 2. Malaria can be transmitted to humans by? & $268(76.8 \%)$ \\
\hline $\begin{array}{l}\text { 3. Do you think malaria can kill a child if un- } \\
\text { treated? }\end{array}$ & $309(88.3 \%)$ \\
\hline $\begin{array}{l}\text { 4 Which of these are ways to prevent and control } \\
\text { malaria? }\end{array}$ & $317(90.7 \%)$ \\
\hline 5. When do malaria mosquitoes feed? & $146(44.6 \%)$ \\
\hline $\begin{array}{l}\text { 6. Where do you seek treatment if when your } \\
\text { child is sick? }\end{array}$ & $205(58.6 \%)$ \\
\hline $\begin{array}{l}\text { 7. How soon after suspecting malaria would you } \\
\text { seek treatment? }\end{array}$ & $119(34.3 \%)$ \\
\hline
\end{tabular}

Table 6: Caregivers' response on knowledge on malaria in children.

The mean knowledge score for all caregivers was 4.82 with a $\mathrm{SD}=1.532$. The minimum and maximum value 1 and 7 respectively.

\begin{tabular}{|l|c|}
\hline Score & Number (\%) \\
\hline High $>4$ & $280(80 \%)$ \\
\hline Low 1 - 3 & $70(20 \%)$ \\
\hline
\end{tabular}

Table 7: Distribution of caregivers' knowledge on malaria.

Caregivers' practices on malaria preventions and treatmentseeking behaviour

Preventive measures caregivers take against malaria

Use of ITN was the main preventive measure by caregivers as 308 (88\%) households possessed at least one bed net. Of this population,210 (68.3\%) children actually slept under the bed net the night before the study.

Other forms protecting their children from malaria were using of chemoprophylaxis, cleaning the surrounding and eating good food. 


\begin{tabular}{|l|c|}
\hline Preventive measures & Number (\%) \\
\hline Sleeping under a mosquito net & $308(88 \%)$ \\
\hline Cleaning the surrounding & $163(46.6 \%)$ \\
\hline Wearing long dresses & $82(23.4 \%)$ \\
\hline Spraying insecticide/repellent & $114(32.6 \%)$ \\
\hline Closing windows and doors & $52(14.9 \%)$ \\
\hline Gauze wire on windows & $36(10 \%)$ \\
\hline Others (use of drugs, good feeding) & $32(9.1 \%)$ \\
\hline
\end{tabular}

Table 8: Caregivers' methods of prevention of malaria in children.

\section{Treatment- seeking behaviour of caregivers}

A majority, [ $n=205$ (58.6\%)], of caregivers sought treatment at the health facility when they suspected malaria in their child. Fewer caregivers $[n=11(3.1 \%)]$ actually went to traditional healers.

\begin{tabular}{|l|c|}
\hline Pace of treatment & Number (\%) \\
\hline Health facility & $205(58.6 \%)$ \\
\hline Traditional healer & $11(3.1 \%)$ \\
\hline Drug shop/pharmacy & $122(34.8 \%)$ \\
\hline Home mgt & $12(3.4 \%)$ \\
\hline Total & $350(100.0 \%)$ \\
\hline
\end{tabular}

Table 9: Where treatment is sought when child present sign/symptoms of malaria.

As many as 119 (34\%)caregivers took their children to a health facility within 24 hours of onset of symptoms while 53(15\%)caregivers went 72 hours after the onset of symptoms. See table 10 below.

\begin{tabular}{|l|c|}
\hline & Number (\%) \\
\hline Within 24 hrs & $119(34.0 \%)$ \\
\hline 2 - 3 days & $178(50.9 \%)$ \\
\hline 4 - 6 days & $32(9.1 \%)$ \\
\hline 7 or more days & $21(6.0 \%)$ \\
\hline Total & $350(100.0 \%)$ \\
\hline
\end{tabular}

Table 10: How soon treatment for malaria is sought.

\begin{tabular}{|l|c|}
\hline Home remedy & Number (\%) \\
\hline Anti-malaria & $54 \%$ \\
\hline Anti-pyretic & $87 \%$ \\
\hline Antibiotic & $36 \%$ \\
\hline Tepid spongy & $63 \%$ \\
\hline Traditional treatment & $15 \%$ \\
\hline Unknown & $32 \%$ \\
\hline Others & $12 \%$ \\
\hline
\end{tabular}

Table 11: Home management.

\section{Discussion}

The prevalence of malaria parasite among under- five children was $49 \%$ in this study area. This finding is higher with regards to the DHS of 2011in Cameroon with a prevalence of 30\%. This difference could be due to the fact that difference RDT devices were employed since as we used carestart RDT which has a higher sensitivity of $90.9 \%$ as compare $45 \%$ for SD Bioline[17].Also, a higher prevalence of $58.2 \%$ was observed in Nigeria by Nwaorgu.,et al.[18].This result was found to be higher than that of a similar study in Madagascar in 2013 with a prevalence of 10\%[19].There was no significant relation between prevalence with gender and age of children. This reflects the equal exposure of these children to Anopheles mosquitoes' bites in the area. This was a similar finding by Nwaorgu.,et al.in Nigeria[18]. However, the age 25-36 months(2-3years) had the greatest prevalence at $46(23 \%)$. This was a similar finding by Nwaorgu who observed that prevalence peaked at 3years with $76 \%$.

With regard to knowledge on the cause of malaria, majority of caregivers $316(90.3 \%)$ correctly attributed mosquito bite as the causeof malaria. This result was similar to those of Terence in Buea 89\%and Faridah in Uganda 88\%[20].Contrary to a study done by Dickson.,et al. in the Northen region of Cameroon were only $27.7 \%$ of participants correctly attributed mosquito bite to malaria.This could be associated to their level of education as only $75 \%$ of that community was educated, unlike this study population with a higher,328 (93.7\%)level of formal education.

Although mosquito was mentioned as the main agent causing malaria by caregivers, some misperceptions such as exposure to sun/too much heat, exposure to dirty water and witchcraft were also observed. In Yaoundé it has been reported that malaria is as a result of excessive heat/sun and witchcraft.In Ghana a similar finding was observed[21,22]. Also in Uganda malaria if believed to be caused by exposure to bad environmental conditions[21]. Too much heat was also reported in Nigeria. This could be associated to their socio-cultural beliefs and also to the environmental conditions as Kumba is hot and humid with an average daily temperature at $27^{\circ} \mathrm{C}$.

The majority ( $100 \%)$ of caregivers mentioned one or more signs and symptoms of malaria. This is of great importance in early presumptive diagnosis and hence early treatment of malaria in children. The most frequent signs/symptoms were fever 332 (94.9\%), Weakness 135 (38.6\%), Vomiting 132 (37.7\%) Loss of appetite 99 (28.3\%) Chills/shivering 94(26.9\%).Thisis similar to a study done by Wakgari in Ethiopia were $97 \%$ of caregivers mentioned fever as the most frequent signof malaria[23], and also by Spencer in Kenya, $>90 \%[24]$.In Cameroon northern region Dickson.,et al. found 
that $61.7 \%$ of participant mention fever. This difference could be explained by the discrepancy in the level of education as earlier mentioned.

Most, 325 (92.9\%), caregivers mentioned mosquito nets as a means of preventing malaria in children.Other methods of prevention were cleaning the surrounding, wearing long dresses to their children, use of insecticides.

There was thus a highlevel of general knowledge on malaria among caregivers as the majority 280 (80\%) of scored high on the total knowledge score.Majority of the population had attended some level of formal education.This could explain the high level of general knowledge on malaria among caregivers. Also it is of great importance; especially in situations where community based health programs need to involve the mothers/caregivers in health interventions such as ICCM.

Studies done by Ahorlu and Tatem have proven that people's perception of the cause of malaria has a strong impact on their preventive measures such as ITN $[22,25,26]$.

Majority302 (88\%) of caregivers in this study area possessed at least one ITN. This is similar to studies done in Buea were $75 \%$ of respondents had an ITN in their homes. In Ethiopia, Wakgariobserved that $93 \%$ of caregivers of under-five children possessed at least one ITN[23]. This was also observed in Uganda 87\%[20]. However, Dickson.,et al. observed $1.2 \%$ of the participants in the Ndu community possessed a mosquito net. The reason here could be the discrepancy in the educational status. However, analysis on the association between educational status and possession of ITN was not significant in this study. This could be due to the massive campaign and distribution of free ITN in 2010 in the country, irrespective of educational status, explaining the high prevalence of $\operatorname{ITN}[27]$.

Among the incorrect methods of prevention eating good food, avoiding too much sun, and also use of chemoprophylaxis with anti malarias such as Coartem, quinine and paracetamol. This finding was also noted in the northwest region, Yaounde, Ghana and Nigeria[18]. This method of indiscriminate us of anti malariafor prevention is discouraged by WHO as it results to increased drug resistance.

As elsewhere in Africa, it was observed that caregivers seek treatment from a variety of sources upon presumptive diagnosis of malaria. In this study area,205 (58.6\%), of caregivers sought treatment at the health facility when they suspected malaria in their child. Others bought drugs from drug shops and managed their sick child at home. Only 119(34\%) of caregiver went to a health facility within 24 hours of onset of symptoms. Most178 (50.9\%) of caregivers sought treatment within 24-36 hoursof onset of symptoms. This is similar to study in Cameroon where $43 \%$ of caregivers said they took their children within 24 hours of onset of symptom[28]. This is however higher as compare to that of Madagascar where on $38 \%$ seek treatment at a health facility[18].

When further interview was done majority of them attempted started management at home either with left over drugs from previous consultations, or drugs bought from drug shops such as paracetamol blood tonics, anti-malarials(quinine, coartem). Other home remedies were tepid sponging in cold water, the use of traditional remedies such as fever grass, manyanga and some herbal preparations (concoctions and purgatives). Thus this implies that home treatment is still a common practice for treatment of malaria in this study area.

To effectively reduce malaria morbidity and mortality in children, treatment seeking behaviour is one of the primary issues that must be addressed. Delay in seeking treatment at the appropriate health facility might result in the progression of the disease to its complicated form, finally resulting to death.

\section{Conclusion}

This study is the first epidemiologic study on childhood malaria in the area and it adds to the existing data on malaria in Cameroon and Sub-Saharan Africa as a whole. Caregivers had a good knowledge of malaria (including its aetiologic agent, signs and symptoms and preventive measures). They also had a good practice towards preventive measures. However, the prevalence of malaria in underfive was high and only a lesser majority of caregivers sought treatment at the health facility in a timely manner.

In the past decades, as never before, it has been widely recognised that malaria control needs a holistic approach, based on the interaction of many disciplines (Brown, 1999). Within this context, studies on treatment-seeking play a vital role for the success of control programmes. As Oaks.,et al. (1991) stated, "it is the behaviour of individuals and groups that determines how or whether efforts to prevent or treat malaria will be successful". 


\section{Recommendations}

- Since as good knowledge on malaria was fond to increase treatment seeking behaviour, we recommend that awareness campaign should be made intensified on the use of mosquito bed nets and in particular on early and appropriate treatment of malaria especially in children underfive, the most vulnerable.

- We also recommend further studies on the factors associated with treatment seeking behaviour in this area. Treatment-seeking needs to beregardedinabroaderconte $\mathrm{xt}$,whichincludespeople'sreal lifesituations economic constraints of coping with treatment costs, in connection with mobilisation of social networks, resource-seeking strategies, gender-related aspects and seasonality.

- Provided that financial constraint is often a factor to seeking treatment in most African settings, the ministry of public health should ensure a regular and constant supply of free treatment for children under five. Also the community should be sensitised on the free treatment of malaria in children under five.

\section{Bibliography}

1. Gay-Andrieu F., et al. "Epidemiological, clinical and biological features of malaria among children in Niamey". Malaria 4 (2005): e10.

2. Barat L., et al. "Do malaria interventions reach the poor? A review through the equity lens". American Journal of Tropical Medicine and Hygiene 71 (200): 174-178.

3. Pluess B., et al. "Malaria-a major health problem within an oil plantation around Popondetta". Malaria Journal 8 (2009): 56.

4. World Malaria Day. "Invest in the Future: Defeat Malaria" (2013).

5. Wang S., et al. "Epidemiology of urban malaria in Dar es Salaam, Tanzania". Malaria Journal 5 (2006): 28.

6. Piet S. "Is Plasmodium vivax still a paradigm for uncomplicated malaria?" 36 (2006): 406-413.

7. Kwadwo A. "People and their health: importance of socioeconomic factors in the control of malaria". Forum Mond Sante 15 (1994): 281-4.

8. WHO. "Global strategy for malaria control". Geneva (1993): 1-14.
9. Cameroon Demographic and Health Survey (2011).

10. MOH. vers un meilleu raccès à la prévention et au traitement du SIDA,de la tuberculose et du paludismeau cameroun.

11. Brahima T., et al. "Prevalence de paludisme dans laire de sente de dango. congo". Epicentre (2012).

12. Demography and statistics. Kumba health district. Kumba: Kumba health district (2010).

13. Molyneux C., et al. "Maternal responses to childhood fevers: a comparison of rural and urban residents coastal Kenya". Tropical Medicine and Health 4.12 (1999): 836.

14. English M., et al. "Acidosis in severe childhood malaria". Quarterly Journal of Medicine 90 (1997): 90.

15. How to use a rapid diagnostic test (RDT): A guide for training at a village and clinic level (Modified for training in the use of the SD Bioline Malaria Ag Pf (2010).

16. Obol J., et al. "Knowledge misconceptions about Malaria among pregnant women in a post-conflict internally displaced persons' camps in Gulu". Malaria Research and Treatment (2011): 1-7.

17. Jeremiah Z. "Field Evaluation of SD Bioline Rapid Malaria Diagnostic Test among Asymptomatic Malaria Infected Children in Port Harcourt, Nigeria". Research Journal of Parasitology 2 (2007): 39-44.

18. Nwaorgu 0 and Orajaka B. "Prevalence of Malaria among Children 1 - 10 Years Old in Communities in Awka North Local Government Area, Anambra State South East Nigeria". African Journals 5.5 (2011): 264-281.

19. L' Institut National de la Statistique INSTAT/Direction, de la Démographie et des Statistiques Sociales (DDSS). Enquête sur les Indicateurs du Paludisme à Madagasca (2013).

20. FARIDAH L. "Knowledge, attitudes and practices on malaria prevention and control in Uganda" (2013).

21. Agyepong I and Manderson L. "Mosquito avoidance and bed net use in the Greater Accra Region, Ghana". Journal of Biosocial Science 31 (1999): 79-92.

22. Agyepong I and Manderson L. "The diagnosis and management of fever at household level in the Greater Accra Region, Ghana". Acta Tropic 58 (1994): 317-330.

23. Wakgari D and Ahmed A. "Malaria-related perceptions and practices of women with under-five children in rural Ethiopia". 
24. Spencer H., et al. "Community- based malaria control in Saradidi, Kenya: description of the progamme and impact on parasitemia rates and anti-malaria antibody". Annuals of Tropical Medicine 81 (1987): 13-23.

25. Ahorlu C., et al. "Sociocultural determinants of treatment delay for childhood Malaria in southern Ghana". Tropical Medicine and International Health 11.7 (2006).

26. Tatem A and Smith D. "International population movements and regional Plasmodium falciparum Malaria elimination strategies". Proceedings of the National Academy of Sciences of the United States of America 107 (2010).

27. Etang J., et al. "Profil entomologique du Cameroun". Rapport Minsanté Cameroun e tOMS. (2007): 1-44.

28. Malaria No More. Cameroon Malaria Knowledge, Attitudes, and Practices (2012).

\section{Assets from publication with us}

- Prompt Acknowledgement after receiving the article

- Thorough Double blinded peer review

- Rapid Publication

- Issue of Publication Certificate

- High visibility of your Published work

Website: www.actascientific.com/

Submit Article: www.actascientific.com/submission.php

Email us: editor@actascientific.com

Contact us: +919182824667 